\title{
Prevention of Cardioembolic Stroke
}

\author{
William David Freeman • Maria I. Aguilar
}

Published online: 3 June 2011

(C) The American Society for Experimental NeuroTherapeutics, Inc. 2011

\begin{abstract}
Cardiac causes of ischemic stroke lead to severe neurological deficits from large intracranial artery occlusion compared to small vessel ischemic stroke. The most common cause of cardioembolic stroke is atrial fibrillation (AF), which has an increasing incidence with age. AF stroke trials demonstrate that anti-coagulation is superior to anti-platelet therapy in terms of ischemic stroke prevention. Recently, warfarin was compared with dabigatran, an oral, direct thrombin inhibitor, and was found to be at least equally effective in reducing ischemic stroke with less intracranial bleeding risk. Future research is investigating other direct thrombin inhibitors as potential alternatives to warfarin, which has a narrow therapeutic index, requires frequent blood monitoring, has multiple drug interactions, and a higher rate of intracranial bleeding. Other causes of cardioembolic stroke include myocardial infarction, left ventricular thrombus, reduced ejection fraction, valvular abnormalities, and endocarditis. Patent foramen ovale is a common finding on echocardiograms in patients with and without stroke (up to $20 \%$ of the population), and it is a controversial source of cryptogenic stroke. The best way to prevent cardioembolic stroke remains early detection and treatment of $\mathrm{AF}$, and treating the underlying stroke mechanism. Cardiac magnetic resonance imaging is an emerging technology and reveals some sources of cardiac embolism
\end{abstract}

Electronic supplementary material The online version of this article (doi:10.1007/s13311-011-0048-y) contains supplementary material, which is available to authorized users.

\footnotetext{
W. D. Freeman

Department of Neurology, Mayo Clinic, Jacksonville, FL, USA

e-mail: freeman.william1@mayo.edu

M. I. Aguilar $(\square)$

Department of Neurology, Mayo Clinic,

Phoenix, AZ 85054, USA

e-mail: aguilar.maria@mayo.edu
}

missed by echocardiography, and might provide an additional diagnostic tool in investigating cardioembolic stroke.

Keywords Cardiac $\cdot$ Stroke $\cdot$ Cardioembolic stroke $\cdot$ Atrial fibrillation $\cdot$ Myocardial infarction $\cdot$ Anti-coagulation

\section{Introduction}

Cardiac embolism causes approximately $20 \%$ of all ischemic strokes [1-3] and is disproportionately more disabling than nonembolic-mechanism stroke, due to occlusion of larger intracranial arteries and larger ischemic brain volume. Atrial fibrillation (AF) remains the most common cause of cardioembolic stroke (Fig. 1) [2-4]. However, there are a variety of other causes of cardioembolic stroke, which include acute myocardial infarction (AMI), ventricular thrombus $(20 \%)$, structural heart defects, cardiac tumors $(15 \%)$, and valvular heart disease (15\%) (Table 1) [3]. The clinical presentation of cardioembolic stroke is typically a sudden onset, as with other types of stroke. However, cardioembolic ischemic stroke may occlude a larger-sized intracranial artery in its resultant vascular territory compared to small vessel disease or perforator vessel disease (e.g., middle cerebral artery [M1] segment occlusion [5]). The sudden onset of neurologic symptoms is not specific for cardioembolism because this overlaps with other stroke causes $[5,6]$. Seizures are more likely to occur from embolism to distal cortical brain tissue compared to small vessel disease infarcts in deep locations. Cardiac thromboembolic events may also share a characteristic radiographic image bycomputed tomography (CT) or magnetic resonance imaging (MRI), which may show a pattern of infarction with a distal cortical "wedge" appearance (Fig. 2; MRI) [7]. Also embolic and cardioembolic events may have a scattered pattern of infarction that suggest an embolus that fractured or 


\section{Atrial Fibrillation (AF)}

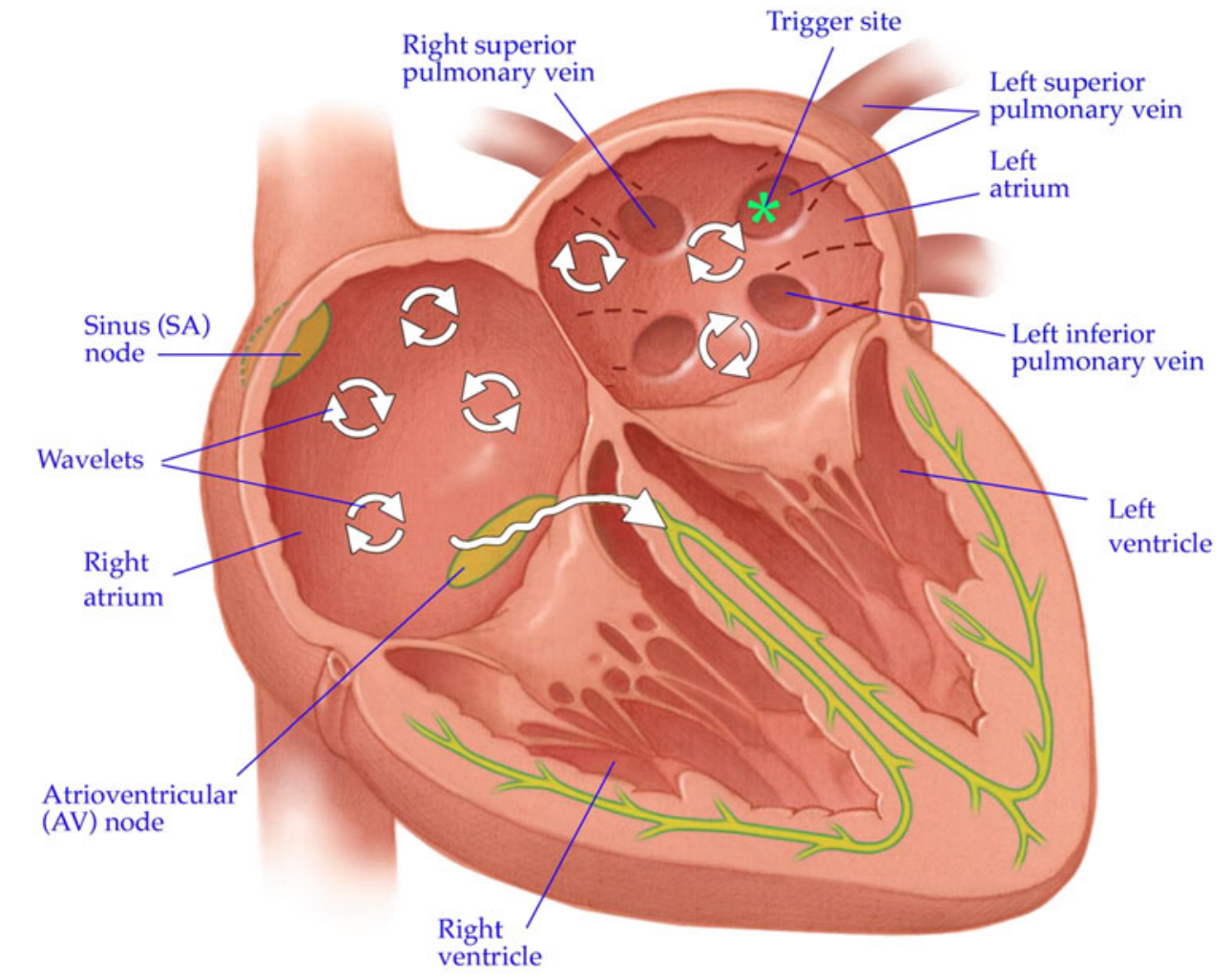

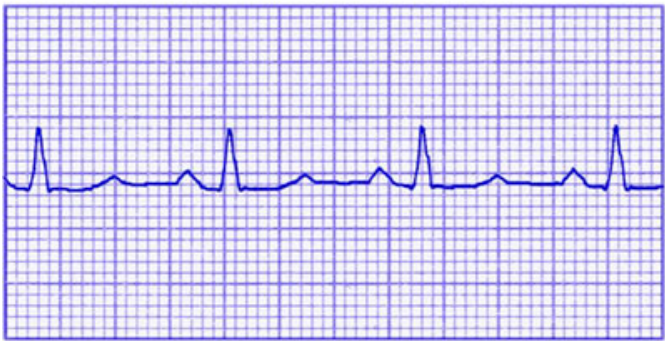

Normal sinus rhythm

Fig. 1 Atrial fibrillation, abnormal electrical excitation pathways that lead to irregular cardiac rhythm, stagnant blood flow in the left atrium, which predisposes to clot formation and potential subsequent

shattered into several pieces and the downstream vascular territory $[6,8]$. Although these radiographic patterns are not pathognomonic for cardiac embolism per se, these patterns typically occur with emboli that travel through the intracranial circulation. Cardioembolic stroke may also present with a "stuttering" or fluctuating neurologic deficits pattern, especially those that display features of alternating right or left hemisphere or anterior and posterior hemisphere localization. Clinical and neuroimaging predictors of cardioembolic stroke include rapid or "dramatic" improvement of a major neurologic deficit [5], a maximal deficit from onset [5, 6], simultaneous ischemic strokes in different vascular territories (especially anterior and posterior circulation), and hemorrhagic transformation of an ischemic infarct that

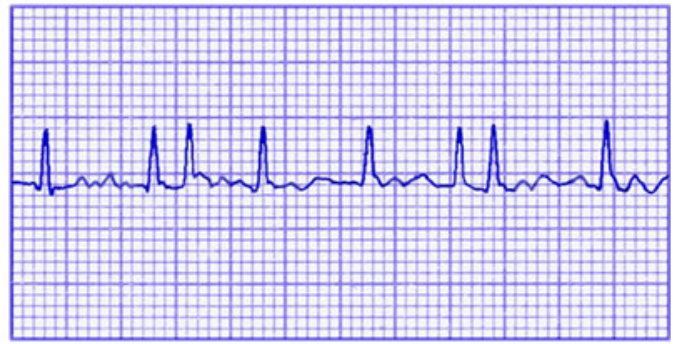

Atrial fibrillation

embolism. (Courtesy of the Mayo Clinic and Foundation for Medictaal Education and Research, Rochester, MN; with permission)

suggests recanalization and reperfusion injury [4]. Transient ischemic attacks (TIAs) are less frequent predecessors of cardioembolic stroke than large-vessel atherosclerotic stroke [5] such as carotid artery to distal artery embolism.

Evaluation of Patients at Risk for Cardioembolic Stroke

The clinical approach to cardioembolic stroke patients is systematic and includes a detailed history, physical examination, neuroimaging, electrocardiogram, and laboratory and echocardiographic data [9]. Asymptomatic patients should be screened during routine annual examinations for risk factors for cardiac embolism by cardiac auscultation for murmurs and assessment for an irregular heart rhythm [9]. 
Table 1 Summary of cardioembolic stroke etiologies, risk, and treatment

\begin{tabular}{|c|c|c|}
\hline Etiology & Ischemic stroke risk & Treatment \\
\hline \multicolumn{3}{|l|}{ Arrythmias } \\
\hline $\mathrm{AF}$ if coexists & $2-18 \%$ per year* (Table 2 ) & Tables 2,4 \\
\hline Sick sinus syndrome [99] & $3.5 \%, 5-10 \%$ if $\mathrm{AF}$ if coexists & C, PM, Table 4 if coexists \\
\hline \multicolumn{3}{|l|}{ Cardiomyopathy [100-115] } \\
\hline Acute MI without AF & $1-2 \%$ in 3 months (AMI $2-6 \%$ ) & $\mathrm{AC}$ \\
\hline LVEF $35-45 \%$ without AF & $2-4 \%$ per year & $\mathrm{AP} v s \mathrm{AC}$ \\
\hline LVEF $<35 \%$ without AF & $1.6 \%$ per year & $\mathrm{AP} v s \mathrm{AC}$ \\
\hline LVEF dysfunction with AF & $2-18 \%$ per year & $\mathrm{AC}$ \\
\hline Left ventricle thrombus & $15 \%$ within 3 months & $\mathrm{AC}$ \\
\hline \multicolumn{3}{|l|}{ Valvular disorders [116-134] } \\
\hline Aortic stenosis & Variable & $\mathrm{AP}, \mathrm{VR}$ if severe \\
\hline Aortic regurgitation & Variable & $\mathrm{AP}, \mathrm{VR}$ if severe \\
\hline Aortic bioprosthetic valve ${ }^{\dagger}$ & Variable & Depends on type of valve and presence of $\mathrm{AF}$ \\
\hline Aortic mechanical valve & $\geq 12 \%$ per year & AC (INR, 2.5-3.5 (most valves) except ball in cage (higher) \\
\hline Mitral rheumatic & $5 \%$ per year & $\mathrm{AC}, \mathrm{C}, \mathrm{VR}$ \\
\hline Mitral rheumatic with AF & $>5 \%$ per year* & $\mathrm{AC}, \mathrm{C}, \mathrm{VR}$ \\
\hline Mitral valve prolapse $[122,123]$ & $1 \%$ & AP \\
\hline Endocarditis [128-133] & Variable & $\mathrm{ABX}, \mathrm{C}, \mathrm{VR}, \mathrm{AP} v s \mathrm{AC}$ \\
\hline Valve prosthesis/replacement [116] & $0.4-1.9 \%$ (without AF) & Depends on valve and AF \\
\hline Mitral valve - bioprosthesic & $1-2 \%$ (without AF) & Depends on valve, presence of AF-AP $v s$ AC \\
\hline Mitral valve - mechanical & $22 \%$ per year & INR, 2.5-3.5 plus ASP \\
\hline PFO [135-137] & Table 5 & AP vs AC, future trials determine whether PFO closure efficacious, safe \\
\hline
\end{tabular}

*Dependent on risk factors (e.g., CHADSvariables, see Table 2). Ischemic stroke risk includes primary and secondary stroke; ${ }^{\dagger}$ aortic tissue valves (porcine or bovine) may receive an initial period of anti-coagulation (depending on the center and treating surgeon) up to 3 months, followed by ant-iplatelet agent (e.g., $81 \mathrm{mg}$ aspirin) thereafter. However, if atrial fibrillation is present, anti-coagulation may be used due to the presence of this risk factor or others (severe low left ventricular ejection fraction). (Modified from Freeman and Aguilar [77, 138] and further references [99-134]) $\mathrm{ABX}=$ antibiotics; $\mathrm{AC}=$ anti-coagulation (international normalized ratio, 2-3 unless indicated); $\mathrm{AF}=$ atrial fibrillation; $\mathrm{AMI}=$ anterior myocardial infarction; $\mathrm{AP}=$ anti-platlet (or aspirin or similar agent); $\mathrm{ASP}=$ aspirin; $\mathrm{C}=$ cardiac consultation; INR $=$ international normalized ratio; $\mathrm{LVEF}=$ left ventricular ejection fraction; $\mathrm{MI}=$ myocardial infarction; $\mathrm{PFO}=$ patent foramen ovale; $\mathrm{PM}=$ pacemaker evaluation; $\mathrm{VR}=\mathrm{valve}$ replacement evaluation (surgery)

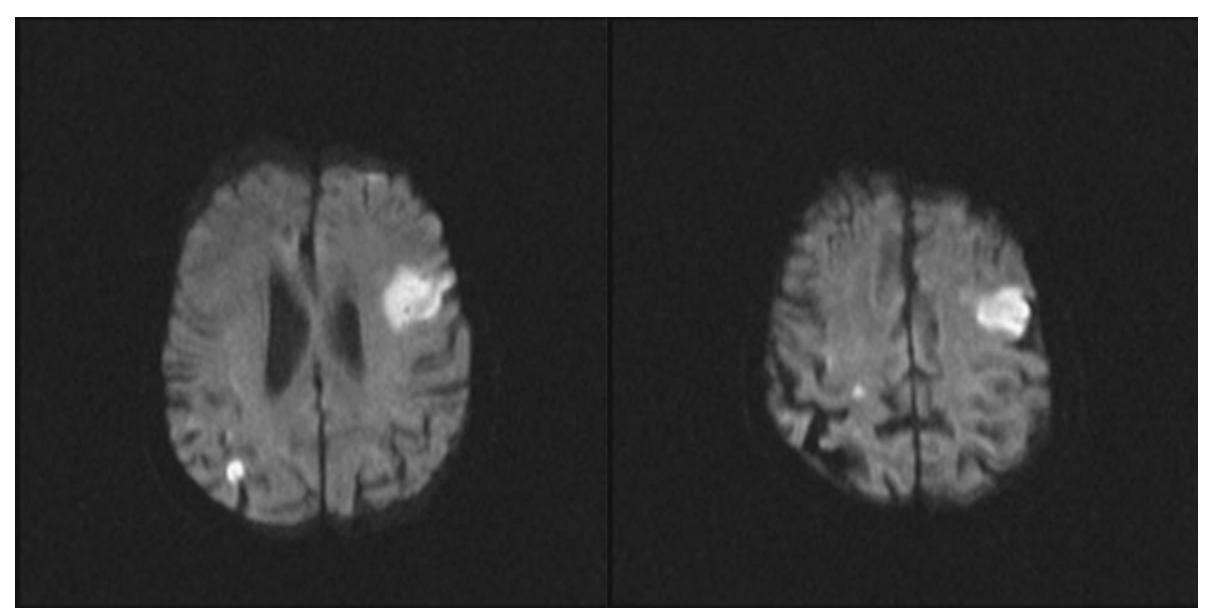

Fig. 2 Diffusion-weighted images of 2 slices of a patient with mitral valve endocarditis and subsequent cardioembolic infarcts. The left frontal infarct has a distal cortical "wedge" appearance typical of cardioembolic or embolic infarcts that travel to the distal cortical arteries. There is also a right parietal infarct as well,which is often seen with cardioembolism (different vascular territories, anterior left and right, and/or posterior circulation). The left-sided image is at a lower slice cut than the right image, which is higher (more cephalad) 
The history should screen for symptomatic palpitations, unexplained bradycardic or tachycardic episodes, assessment of the patient's history of cardiac disease or heart failure, and family history of cardiac disease or arrhythmias. The history and physical examination may disclose a potential risk factor or cause for cardioembolic stroke, such as AF. However a substantial number of patients who present with stroke will not display AF during the inpatient setting, even on telemetry, but may require prolonged monitoring, such as Holter monitoring or event monitoring to detect occult AF. In such patients with a high degree of clinical suspicion for arrhythmia, a 12-lead electrocardiogram, inpatient telemetry, or outpatient Holter monitor [10] or event recorder may be necessary to capture intermittent paroxysmal AF or sick sinus syndrome. Prolonged outpatient Holter monitoring up to 7 days can also be considered for patients with unexplained cerebral ischemia, which had a higher yield of occult AF detection compared to 24-h or 28-h Holter monitoring (12.5\% compared with 4-6\%) [11].

The key to preventing cardioembolic stroke is early recognition of risk factors before an actual stroke occurs. Patients with dyspnea should be considered for myocardial infarction, angina, or heart failure. Patients with TIA symptoms after Valsalva (e.g., cough, sneeze, bowel movement)are suggestive of intracardiac shunt or other possible sources of embolism (e.g., large patent foramen ovale or atrial or ventricular septal defects). In such cases, echocardiogram with a bubble study or alternative means of detecting shunt physiology may disclose this source of potential cardiac embolism.

Standard laboratory investigations include complete blood cell count with platelets, prothrombin time, and activated thromboplastin time [9]. Young patients without vascular risk factors who experience cardioembolic stroke or especially TIA, and who have a family history suggestive of thrombophilia, should undergo a prothrombotic workup. A standard prothrombotic laboratory workup for younger patients includes GP20210 (prothrombin gene) mutation, factor V Leiden mutation, protein $\mathrm{C}$ or $\mathrm{S}$ deficiency, anti-thrombin III deficiency, anti-phospholipid antibodies, and lupus anticoagulant. Recently, hypercoaguable blood testing has come into question, given recent meta-analyses showing a weak association with arterial stroke [12]. However, this may be considered in young patients with no other cause of stroke. In addition, paradoxical embolism should be considered in patients in whom Deep vein Thrombosis (DVT) is detected with a known intracardiac shunt with cardioembolic event or stroke.

In patients with symptomatic, incident stroke, echocardiography is advised to evaluate the source of cardioembolism. Transesophageal echocardiogram (TEE) remains the diagnostic "gold-standard" to evaluate cardioembolic sources of stroke $[9,13,14]$. TEE has been shown to be superior to transthoracic echocardiography (TTE) in detecting cardiac sources of embolism [14]. Some clinicians prefer to perform TTE first, and if positive for cardioembolic stroke proceed with treatment, depending on the cause. However, if TTE is negative and TEE is not obtained, it is possible to fail to identify the source of cardiac embolism $[15,16]$. The risks of TEE include local irritation or injury to the oropharynx and esophagus; respiratory decompensation, especially in those with poor cardiopulmonary status (e.g., end-stage cardiopulmonary disease); increasing intracranial pressure, in patients who are at risk. The sensitivity for both TTE and TEE in detecting right-to-left shunting can be doubled by intravenous injection of saline mixed with air (i.e., the saline bubble study). Saline bubble study transcranial Doppler ultrasonography can also detect right-to-left shunting when intravenous microbubbles are detected as they pass through the middle cerebral artery segment (M1) [17].

Neuroimaging of cardioembolic stroke is typically performed acutely via noncontrast head CT for patients presenting to the emergency room. Noncontrast head CT is typically used due to its wide availability, quick turnaround time, and ability to exclude intracranial hemorrhage [9]. Noncontrast head CT is also typically used in the decisionmaking process regarding eligibility for intravenous tissue plasminogen activator (TPA) for patients who present within 3 hours of symptom onset. However, patients who present with subacute to chronic stroke symptoms or TIA, or when $\mathrm{CT}$ is nondiagnostic, MRI is often used. MRI with diffusionweighted image sequences has superior sensitivity in detecting small areas of ischemia or infarction that are often missed on initial CT, particularly in the posterior fossa. The neuroimaging pattern of a cardioembolic infarct is typically a cortical or a cortical-subcortical pattern of ischemia on diffusion-weighted imaging, if acute (Fig. 2). In comparison, small deep penetrator infarcts of the lenticulostriate or brainstem $(<1 \mathrm{~cm}$ in size) are typically not cardioembolic in origin and most likely relate to small vessel $(\leq 100$ microns in diameter) disease processes, such as hypertension or diabetes. However, reports of migratory cardioembolic events that occlude penetrating vessel ostia are reported, but their involvement is typically greater than $1 \mathrm{~cm}$ in parenchymal size. Cardioembolic stroke affecting the posterior circulation accounts for $\leq 25 \%$ of posterior circulation ischemic events in some registries [18-26].

Once a systematic stroke workup has been completed, it is important to classify the stroke mechanism. Understanding the mechanism of stroke is important because evidence-based recommendations are based on mechanism. The authors suggest classifying stroke mechanism by the modified trial of ORG 101172 (TOAST) classification [27], which subdivides stroke into 5 subtypes based on clinical features and the results of diagnostic tests: 1) large-artery atherosclerosis, 2) cardioembolism, 3) small-vessel occlusion, 4) stroke of other known cause, and 5) stroke of unknown cause (cryptogenic). The article will primarily focus on cardioem- 
bolic stroke and AF, because it is the most common cause of cardioembolism. The remainder of the article will summarize treatments for other causes of cardioembolic stroke.

Newer methods are being reported to help detect cardioembolic stroke. For example, long-term continuous electrocardiographic monitoring or 30-day event recorders show a 9$23 \%$ detection rate of occult $\mathrm{AF}$ among those without known AF or with previously diagnosed cryptogenic stroke [28-30].

B-type natriuretic peptide (BNP) elevation had risen to $>76$ at stroke admission and had an odds ratio of 2.3 times that being associated with cardioembolic stroke compared to other types (confidence interval [CI], 1.4-3.7; $p=0.001$ ) [31], and BNP elevation was highest in cardioembolic stroke (as high as $410 \mathrm{pg} / \mathrm{ml}$ ) among all stroke subtypes [32].

\section{Stroke Prevention in AF}

Atrial fibrillation (AF) is the most common source of cardiac embolism $(\sim 45 \%)$ and has an incidence that increases with age [33-35]. Approximately 2.3 to 3.2 million people are currently affected in the United States, and based on epidemiologic data from Olmsted County, the future projections of patients with AF could exceed 12 million by 2050 [33], which has tremendous potential on society and healthcare costs attributed to stroke.

According to the American College of Cardiology, the American Heart Association, and the European Society of Cardiology, $\mathrm{AF}$ is classified into different forms [34]: 1) paroxysmal AF (PAF), a self-terminating or intermittent form that generally last less than 7 days and usually less than 24 hours; 2) persistent AF, which fails to self terminate and lasts longer than 7 days; and 3) permanent $\mathrm{AF}$, which lasts for more than 1 year. However, it is important to note that the ischemic stroke risk is similar between persistent, sustained, and PAF based on data within the Atrial Fibrillation Clopidogrel Trial with Irbesartan for Prevention of Vascular Events (ACTIVE W) [36, 37]. Detection of PAF can also be particularly elusive and sometimes it is first detected during embolic stroke.AF causes ineffective atrial contractions, which lead to stagnation of blood within the left atrium and within the left atrial appendage, which later embolizes to the brain and sometimes viscera. Another classification for AF is either "valvular" or "nonvalvular" AF. Valvular AF refers to AF in the setting of mitral valve disease (e.g., rheumatic mitral valve stenosis) or prosthetic valve [34]. Nonvalvular AF refers to AF without any underlying structural valve disease or prosthetic valve. Nonvalvular AF occurs in approximately $0.7 \%$ of the general population and increases with age $[35,38,39]$.

$\mathrm{AF}$ ischemic stroke risk is stratified by concomitant independent risk factors, including age ( $>75$ years), history of prior transient ischemic attack or stroke, hypertension, diabetes, and heart failure. Multiple studies have identified these risk factors for stroke in patients with AF. These include the Atrial Fibrillation Investigators (AFI), the Boston Area Anticoagulation Trial of Atrial Fibrillation Investigators (BAATAF) [40], Stroke Prevention in Atrial Fibrillation (SPAF) [41, 42], Stroke Prevention in Nonrheumatic Atrial Fibrillation (SPINAF), Copenhagen Atrial Fibrillation, Aspirin, and Anticoagulation Study (AFA-SAK) [43], and Canadian Atrial Fibrillation Anticoagulation (CAFA) study [44]. Several stroke risk stratification schemes have been proposed [45, 46], and one scheme has not been definitely proven superior to another scheme or $100 \%$ predictive of ischemic stroke risk $[45,46]$. For clinical purposes, we find the CHADS2 risk stratification scheme [46] easy to use in patients identified with AF. CHADS is an acronym of the particular risk factor and is weighed for each to estimate the annual ischemic stroke risk (Table 2) (congestive heart failure [1 point]; hypertension particularly uncontrolled [1 point]; age $>75$ years [ 1 point]; diabetes [1 point]; and stroke or transient ischemic attack [2 points]) [46]. We find the CHADS2 scale simple and easy to use, especially when discussing the riskbenefit ratio of anti-coagulation therapy.

\section{Anti-Platelet Versus Anti-coagulation Therapy for AF} Stroke Prevention

Several large prospective trials and meta-analyses have demonstrated warfarin superioritycompared to aspirin therapy in reducing stroke for high-risk AF patients [47-60]. Review of data comparing warfarin to anti-platelet agents will not be reiterated here, but references are provided to the reader [47-61]. Generally speaking, the optimal therapy for each patient is individualized based on ischemic stroke risk factors against hemorrhage risks, such as prior intracranial hemorrhage or gastrointestinal bleeding.

Table 2 CHADS2 atrial fibrillation risk stratification scheme

\begin{tabular}{ll}
\hline CHADS2 score & NRAF adjusted stroke rate $(95 \% \mathrm{CI})^{*}$ \\
\hline 0 & $1.9(1.2-3.0)$ \\
1 & $2.8(2.0-3.8)$ \\
2 & $4.0(3.1-5.1)$ \\
3 & $5.9(4.6-7.3)$ \\
4 & $8.5(6.3-11.1)$ \\
5 & $12.5(8.2-17.5)$ \\
6 & $18.2(10.5-27.4)$ \\
\hline
\end{tabular}

*Risk of stroke in the National Registry of Atrial Fibrillation (NRAF) participants, stratified by CHADS2 score. CHADS2 is a mnemonic for congestive heart failure ( 1 point), hypertension ( 1 point), age of 75 years or older (1 point), diabetes mellitus (1 point), and stroke or transient ischemic attack (2 points). Modified from Gage et al. [46]; adjusted stroke rate is calculated from an exponential survival model, assuming aspirin was not used

$\mathrm{CI}=$ confidence interval 
Several recent studies comparing newer anti-platelet agent clopidogrel against warfarin (ACTIVE trial) will be discussed, as well as the Randomized Evaluation of Long-Term Anticoagulant Therapy (RELY) trial studying dabigatran against warfarin in $\mathrm{AF}$ patients.

The ACTIVE A trial [62] and ACTIVE $\mathrm{W}$ trial [36] investigated the role of aspirin and clopidogrel against AFrelated thromboembolic events and hemorrhagic events. The ACTIVE A trial studied 7554 patients with AF at risk for stroke who were unsuitable for warfarin anticoagulation taking clopidogrel (75 mg daily) or a placebo in addition to aspirin (75-100 $\mathrm{mg}$ daily) [62]. The primary outcome measure was a composite endpoint of stroke, myocardial infarction (MI), extra-cerebral embolic events, and vascular death. The combination therapy of aspirin and clopidogrel reduced the risk of ischemic stroke (relative risk [RR], 0.72; 95\% CI, 0.62-0.83; $p<0.001)$ and myocardial infarction (RR, $0.78 ; 95 \% \mathrm{CI}, 0.59-1.03 ; p=0.08$ ), but also increased the risk of major bleeding in the clopidogrel group (2.0\% per year) compared to aspirin-placebo group (1.3\% per year) (RR, 1.57; 95\% CI, $1.29-1.92 ; p<0.001)$.

The ACTIVE $\mathrm{W}$ trial [36] randomized more than 6600 patients with $\mathrm{AF}$ with at least 1 risk factor for stroke to both aspirin (75-100 mg daily) and clopidogrel (75 mg daily) against dose-adjusted warfarin (target international normalized ratio [INR], 2.0-3.0). The primary outcome measure for the study was incident stroke, extra-cerebral embolic event, MI, and vascular death. The study was stopped early due to the findings of superiority of oral anti-coagulation compared to the aspirin-clopidogrel group in preventing primary events (RR, 1.44; 95\% CI, 1.18-1.76; $p=0.0003$ ), and less major bleeding with oral anti-coagulation therapy (RR, 1.30; 95\% CI, 0.94-1.79; $p=0.03$ ). These data from the ACTIVE studies suggest clopidogrel and aspirin reduces ischemic stroke and MI (stroke rate per year, $2.4 \%$ for clopidogrel plus aspirin $v s 3.3 \%$ for aspirin alone), but at the cost of increased bleeding events compared to aspirin alone (major bleeds per year, $2.0 \%$ for clopidogrel and aspirin $v s 1.3 \%$ for aspirin alone). Also the combination of aspirin and clopidogrel increases bleeding risk compared to warfarin (major bleeds, $2.42 \%$ vs $2.21 \%$ per year, respectively) and is inferior to oral anti-coagulation in preventing ischemic stroke ( $2.1 \%$ vs $1.0 \%$ per year, respectively).

The Birmingham Atrial Fibrillation Treatment of the Aged (BAFTA) trial [63] is another recent important study. BAFTA studied 973 patients aged 75 years or older with AF.The study randomized patients to either low-dose aspirin $(75 \mathrm{mg} /$ day) or dose-adjusted warfarin (target INR, 2.0-3.0). The primary endpoint was ischemic stroke, fatal or disabling hemorrhagic event (such as intracranial hemorrhage [ $[\mathrm{ICH}]$ ), or clinically significant arterial embolic event.The mean period of follow-up was 2.7 years in a primary care setting in the United Kingdom. The primary event rate was $3.8 \%$ per year in the aspirin group compared to $1.8 \%$ per year in the warfarin group (RR, $0.48 ; 95 \% \mathrm{CI}$, $0.28-0.80 ; p=0.003)$. The annual absolute risk reduction using warfarin compared to aspirin was only $2 \%(95 \% \mathrm{CI}$, 0.7-3.2). However, it is important to note this study included all AF patients, regardless of stratified risk (e.g., CHADSscale).The findings demonstrate a "net clinical benefit" ("fatal or disabling stroke" regardless of ischemic or hemorrhagic origin) in older patients $(48 \%$ RR reduction) in overall stroke events treated with warfarin compared to aspirin. The annual risk of extracranial bleeding was similar but slightly higher in the aspirin group (i.e., $1.6 \%$ in the aspirin group compared to $1.4 \%$ in the warfarin group [RR, 0.87; 95\% CI, 0.43-1.73]).

The Anticoagulation and Risk Factors in Atrial Fibrillation (ATRIA) trial by Singer et al. [64] demonstrated a net clinical benefit of warfarin anti-coagulation in older patients with AF, despite hemorrhagic events [64]. There were 13,559 adult patients with nonvalvular AF who were studied in both retrospective and prospective components. The The Anticoagulation and Risk Factors in Atrial Fibrillation (ATRIA) study used the CHADS2 score to estimate embolic stroke risk. A net clinical benefit was assessed by determining the annual rate of ischemic strokes and systemic emboli prevented by warfarin minus ICH attributable to warfarin, multiplied by an impact factor. An impact factor of 1.5 was used for ICH. The study demonstrated a net benefit of warfarin in AF patients increasing with CHADS2 score, starting from 0 and increasing to 6 , even when accounting for ICH and in older patients.

What about newer anticoagulants for AF? Ximelegatran, a direct thrombin inhibitor, was studied in Stroke Prevention using Oral Thrombin Inhibitor in atrial Fibrillation (SPORTIF) III and V trials, but had complications of hepatic dysfunction and was not approved for use by the United States Food and Drug Administration [65-67]. The drug was not inferior to warfarin in reducing ischemic stroke in $\mathrm{AF}$ patients and had a relatively low incidence of bleeding similar to warfarin.In the SPORTIF trials, ximelegratran had similar rates for major hemorrhage (gastrointestinal and gastric ucler tract and soft tissues) of approximately $2.5 \%$ per year to warfarin.

The Randomized Evaluation of Long-Term Anticoagulant Therapy (RELY) trial [68] studied dabigatran (Pradaxa TM, Boehringer Ingelheim, Rhein, Germany), another oral direct thrombin inhibitor in AF patients. The study randomized 18,113 patients with $\mathrm{AF}$ at risk for ischemic stroke to either dabigatran (fixed doses of 110 or $150 \mathrm{mg}$ twice a day in blinded fashion) or dose-adjusted warfarin (unblinded). The primary outcome was stroke or systemic embolism. The median duration of follow-up was approximately 2 years. The primary outcome occurred in $1.69 \%$ per year in the warfarin group compared to $1.53 \%$ in the dabigatran 
group (with $110 \mathrm{mg}$ ) (RR with dabigatran, 0.91; 95\% CI, $0.74-1.11 ; p<0.001$ for noninferiority) and $1.11 \%$ per year in the dabigatran group (with150 mg) (RR, 0.66; 95\% CI, $0.53-0.82 ; p<0.001$ for superiority). Major bleeding was reported in $3.36 \%$ per year in the warfarin group compared to $2.71 \%$ in the dabigatran group (with $110 \mathrm{mg})(p=0.003$ ), and $3.11 \%$ per year in the dabigatran group (with $150 \mathrm{mg}$ ) $(p=0.31)$. ICH occurred at a rate of $0.38 \%$ per year in the warfarin group compared to $0.12 \%$ per year in the dabigatran group (with $110 \mathrm{mg})(p<0.001)$, and $0.10 \%$ per year in the dabigatran group (with $150 \mathrm{mg})(p<0.001)$. The data suggest the dabigatran group (with $110 \mathrm{mg}$ dose) was not inferior to the dose-adjusted warfarin for stroke prevention, and had less major bleeding complications, particularly ICH $(0.38 \%$ warfarin $v s \quad 0.12 \%$ with $110 \mathrm{mg})$. The higher dose of dabigatran (with $150 \mathrm{mg}$ ) was superior to warfarin in ischemic stroke prevention, and had less ICH than warfarin $(0.38 \%$ per year with warfarin $v s 0.10 \%$ per year with $150 \mathrm{mg}$ oral dabigatran), but it had similar rates of extracranial major hemorrhage $(3.36 \%$ per year with warfarin $v s 3.11 \%$ per year with $150 \mathrm{mg}$ dabigatran).

Dabigatran has some advantages in comparison to warfarin, which includes the lack of frequent blood draws to monitor levels (as seen with patients on warfarin) and avoidance of the many drug interactions that warfarin has with other substances (herbal and dietary) (Table 3). The drug also may be preferred in some patients in which there is concern of potential ICH, given its lower risk (0.1$0.12 \%)$ than dose-adjusted warfarin $(0.3 \%$ per year $)$. However, it should be noted that dabigatran needs to dose-adjusted with renal function and interacts with amiodarone (a P-gp inhibitor), which is commonly used in AF patients. Other P-gp inhibitors ketoconazole, verapamil, quinidine, and clarithromycin do not require dose adjustments. The drug is also a category $\mathrm{C}$ in regard to pregnancy. The effects of dabigatran are reduced by rifampin which is a P-gp inducer. The dose used for patients with a creatinine clearance of greater than $30 \mathrm{~mL}$ per minute is $150 \mathrm{mg}$ orally twice daily, whereas per patients with a creatinine clearance of 15 to $30 \mathrm{~mL}$ per minute issuggested at $75 \mathrm{mg}$ orally, twice daily[69]. The half-life of dabigatran is approximately $12 \mathrm{~h}$, and there is no known "anti-dote" to reverse its effects if lifethreatening bleeding occurs [69]. Dabigatran does not require blood monitoring, which would make assessing compliance difficult in some patients. The drug will also be more expensive than warfarin. However, because it will not require frequent and lifelong blood monitoring like warfarin, the long-term cost $v s$ warfarin (especially frequent) monitoring remains to be clearly outlined. Dabigatran was approved by the United States Food and Drug Administration in 2010 for use in AF patients for stroke prevention [70], and it was available for prescription by mid-November to December 2010. The drug has been approved and available for use in Europe (prior to approval in the United States) for venous thromboembolism prevention after knee replacement (at a dose of $110 \mathrm{mg}$, twice a day), which was not for stroke prevention.

Dabigatran prolongs the activated partial thromboplastin time (aPTT) [69]. In patients with bleeding, the aPTT test may determine if the drug is present or not, or to assess drug compliance. In areas that in which it is available, a thrombin time or ecarin clotting time may be more sensitive in evaluating, and with the anti-coagulant effects of the drug. The prothrombin time (PT) is also prolonged by this drug, but is less sensitive than eclarin clotting time and is not deemed suitable for assessing the anti-coagulation effect of the dabigatran [69]. The drug can be dialyzed, and as mentioned there is no anti-dote to reverse its effects. The manufacturer suggests providing sufficient intravenous

Table 3 Advantages and disadvantages of dabigatran and warfarin

\begin{tabular}{lll}
\hline Drug & Advantages & Disadvantages \\
\hline Warfarin & - Cheap, generic anti-dotes known* & - Multiple drug-substance interactions \\
& & - Frequent blood draws to monitor (costs) \\
& - Long half-life ( $\sim 40$ hours) \\
& - Adjustments based on hepatic and other interactions, functions \\
Dabigatran & - Little to no monitoring & - Expensive, but may offset long-term laboratory costs \\
& - Lower bleeding risks (compared to warfarin) & - No generic \\
& & - Interacts with amiodarone \\
& & - Half-life (12-h) \\
& - Adjusted for renal function and moderate hepatic impairment
\end{tabular}

*Warfarin reversal anti-dotes include discontinuation of the drug, vitamin $\mathrm{K}$, and in emergencies fresh frozen plasma, prothrombin complex concentrates, and possibly recombinant factor VIIa 
fluids to maintain diuresis because the drug has a renal elimination route.

The treatment approach for AF patients between aspirin and warfarin anti-coagulation (or in the near future with dabigatran in the United States) should be individualized based on the patient's ischemic stroke risk, hemorrhagic risk, and other factors. Consensus guidelines for treatment are shown in Table 4. However, "one size fits all" model does not apply to many patients. For example, a 75-yearold patient with AF who had no other risk factors may not be recommended anti-coagulation by current consensus, but results from the BAFTA trial suggest a small absolute benefit (absolute risk reduction, 2\%) over aspirin. Another example is a 76-year-old patient with $\mathrm{AF}$, hypertension, diabetes, prior TIA, and no congestive heart failure would have a CHADS2 score of 4 or annual ischemic stroke risk of approximately $8.5 \%$. This patient's estimated ICH risk is approximately 0.3 to $1 \%$ annually [63-68, 71]. This patient's "risk-benefit ratio" favors anti-coagulation with either warfarin or dabigatran over aspirin (or clopidogrelaspirin combination) for ischemic stroke prevention based on the aforementioned trials. However, other variables need to be considered, such as the patient's ability to take warfarin and return for frequent blood monitoring (e.g., compliant patients who can afford such medication and laboratory testing).Some health insurance companies may not cover dabigatran initially, especially if warfarin is cheaper, although the long-term costs of frequent blood testing may offset the cost of the drug. Also patients with $\mathrm{ICH}$ and AF may not be suitable for warfarin, especially those with cerebral amyloid angiopathy. The dilemma of starting or re-starting anti-coagulation after ICH is outside the scope of this article.

\section{Other Treatment Options for AF}

Other drugs currently under investigation include factor Xa inhibitors (rivaroxaban and apixaban).However, these drugs have not been approved by the Food and Drug Administration at the time of this writing. It should be noted the results of the Apixaban versus Acetylsalicylic Acid to Prevent Strokes (AVERROES) trial [72] were recently completed, which randomized 5599 patients with AF to either apixiban (5 mg orally, twice a day) or aspirin (81$325 \mathrm{mg}$ ) for stroke prevention, and compared stroke and other embolism as the primary endpoint and major bleeding events. Mean follow-up was approximately 1 year, but the study terminated earlier due to clear benefit of apixiban compared to aspirin. Apixiban was superior to aspirin in stroke prevention (i.e., primary endpoint of stroke, 1.6\% per year among apixiban patients and 3.7\% per year with aspirin). Major bleeding rates were similar (1.4\% per year in the apixaban group and $1.2 \%$ per year in the aspirin group), with similar rates of intracranial hemorrhage (11 patients $[\sim 0.3 \%]$ on apixiban, and $13[0.4 \%]$ on aspirin).

A newer drug termed tecarfarin (ATI-5923) has been recently studied by Ellis et al. [73], is an oral vitamin $\mathrm{K}$ antagonist similar to warfarin. However, tecarfarin is a vitamin $\mathrm{K}$ epoxide reductase antagonist, which is metabolized by carboxylesterases and not the cytochrome P450 (CYP450) system like warfarin. Nonetheless, the drug acts like warfarin by elevating the INR, and it can be measurded as such similar to warfarin. This difference in metabolism can also decrease many potential drugs, herbal, and dietary interactions seen with warfarin due to the CYP450 system. Because the drug may not involve the CYP450 2 C9 gene polymorphisms, this may lead to more stable anticoagulation control, especially in patients with genetic polymorphisms of the CYP450 2 C9 system. However, the study by Ellis et al. [73] is limited in that it was only an open-label study whose primary outcome was time in the therapeutic range. Nevertheless, the drug provides insight into other pharmacotherapeutic options in the research and development pipeline for patients with AF.

Newer surgical or interventional options are described for AFand include the Maze procedure, and other atrial occluder interventions, including the WATCHMAN, PLAATO, and Amplatzer devices [74, 75]. These devices are typically used in AF patients who cannot tolerate prolonged anti-coagulation therapy. These devices also carry initial surgical or endovascular risks not seen with medical therapy. Although these interventions have shown feasibility, their long-term superiority to medical management remains a matter of debate $[74,75]$. It appears to

Table 4 Consensus treatment recommendations for patients with AF combined with CHADS2 score equivalents*

- Aspirin 81-325 mg daily for patients with no risk factors

- Aspirin 81-325 mg daily or warfarin (INR: 2-3) for patients with one moderate risk factor (i.e.

- Warfarin (INR: 2-3) for patients with any high-risk factor or more than 1 moderate risk factor (i.e. or contraindication to warfarin

CHADS2 score of 1)

CHADS2 score $\geq 2$ )

*Modified from references [34, 61]

Moderate-risk factors include age $\geq 75$ years, hypertension, heart failure, left ventricular ejection fraction(LVEF) $\leq 35 \%$, or diabetes mellitus. Highrisk factors include prior stroke, transient ischemic attack or embolism, mitral stenosis, or mechanical heart valve. Patients with mechanical heart valves should have their international normalized ratio (INR) intensity adjusted depending on location and other factors.

$\mathrm{AF}=$ atrial fibrillation 
make sense that exclusion of the left atrial appendage and subsequent thrombus formation may reduce ischemic stroke risk.However, at the present time we encourage enrollment in clinical trials to help to scientifically determine whether these surgeries or procedures are superior to medical management. Conversely, patients who cannot tolerate long-term anti-coagulation may be considered on a case by case basis for such surgical or interventional devices in clinical trials [76].

\section{Stroke Prevention in Other Causes of Cardioembolic Stroke}

Other causes of cardioembolic stroke include myocardial infarction, left ventricular thrombus, low ventricular ejection fraction, cardiac tumors, and prosthetic heart valves [36, 38-40]. Treatment recommendations for other cardioembolic sources with anti-coagulation and anti-platelet agents are summarized in Tables 1 and 4. For a comprehensive review of other causes of cardioembolic stroke and management, see Freeman and Aguilar's [77] article.

\section{MI}

MI and ischemic cardiac disease are the leading cause of death in the United States.Cardioembolic strokes may occur within 24 hours after MI. Approximately half of cardioembolic strokes occur within the first week, although stroke risk remains high for as many as 3 months post-MI before decreasing gradually [78-84]. Myocardial infarction that involves the anterior myocardial wall carries a higher stroke risk than inferior wall myocardial infarction (25\% vs 5\%) [84]. Patients who have experienced MI from coronary artery disease are often treated with heparin, which also reduces the risk of ventricular wall thrombus formation [79-81, 84]. Patients with anterior wall MI with ventricular wall thrombus should be treated with warfarin, with the goal of attaining an INR of 2.0 to 3.0 for as many as 6 months [84]. Subsequently, aspirin therapy may be used if ejection fraction is preserved and AFis absent. The Anticoagulants in the Secondary Prevention of Events in Coronary Thrombosis (ASPECT) trial [80] demonstrated reduced stroke risk for as much as $40 \%$ during a 3 -year time span in patients treated with prolonged anticoagulation after myocardial infarction, although bleeding risks were increased. If $\mathrm{AF}$ develops after myocardial infarction, anti-coagulation may be considered indefinitely, depending on other risk factors, as assessed by the CHADS 2 score [84]. If stroke occurs after MI despite antithrombotic therapy, the patient's stroke mechanism and risk needs to be re-evaluated, especially to ensure that adequate medical prophylaxis is used. For example, the severity of left ventricular ejection fraction $(<35 \%)$, the presence of ventricular wall thrombus, whether anticoagulation was therapeutic or not, and the presence of $\mathrm{AF}$ or another cause of the patient's stroke, such as carotid disease, need to be considered. Discovering the mechanism of a stroke after MI should lead to appropriate therapeutic intervention assuming there is no contraindication (e.g., AF, after MI and stroke, leads to anti-coagulation).

\section{Patent Foramen Ovale (PFO)}

PFO remains a controversial cause of cryptogenic and cardioembolic stroke due to its widespread prevalence in the population of approximately 20 to $25 \%$ [77]. A PFO is a hole between the left and right atria and allows passage of blood from the right to left side depending on the size of the PFO and physiological variables, such as Valsalva, which increases intrathoracic pressure. The PFO remains controversial because of its high prevalence and because common physiologic stressors frequently occur that do not result in immediate ischemic stroke. Nonetheless, the association of a PFO with atrial septal aneurysm (ASA) has been suggested in prospective trials of patients with cryptogenic (e.g., mechanism not certain due to AF or another mechanism, such as carotid stenosis) (Table 5). The ASA is a mobile structure that bows back and forth around the PFO and is hypothesized to be a nidus for clot formation, although rarely substantiated on echocardiogram [77, 85-87].

For patients with incident stroke and PFO detected on echocardiogram and no other attributable cause (i.e., lacunar disease mechanism or large vessel atherosclerosis) with a cryptogenic stroke classification, we advise evaluation for ASA on echocardiogram and use of aspirin or antiplatelet initially, along with another risk factor modification. For patients who fail this approach, we recommend enrollment in a clinical trial studying medical management vs endovascular PFO closure [88]. Recently, the CLOSURE-1 trial preliminary results were released [89]. The CLOSURE 1 trial [90] was a prospective, multicenter study

Table 5 Risk of recurrent stroke in patients with initial cryptogenic stroke ages 18 to 55 years* with echocardiographic findings ${ }^{\dagger}$

\begin{tabular}{ll}
\hline Echocardiographic finding & Risk for recurrent stroke \\
\hline No PFO or ASA & $4.2 \%(95 \%$ CI, $1.8 \%-6.6 \%)$ \\
PFO without ASA & $2.3 \%(95 \% \mathrm{CI}, 0.3 \%-4.3 \%)$ \\
PFO with ASA & $15.2 \%(95 \mathrm{CI}, 1.8 \%-28.6 \%)$ \\
\hline
\end{tabular}

$*$ See references $[135,136] ;^{\dagger}$ Adapted from Freeman and Aquiler [77] $\mathrm{ASA}=$ atrial septal aneurysm; $\mathrm{CI}=$ confidence interval; $\mathrm{PFO}=$ patent foramen ovale 
of closure of the PFO using the STARFLEX PFO occluder device, combined with the best medical therapy, compared to best medical therapy alone in patients with symptomatic TIA or stroke who had known PFO. The study enrolled 910 patients and required a 2-year follow-up. The primary endpoint of the CLOSURE 1 trial was a 2-year incidence of stroke or TIA, all-cause 30-day mortality,and neurologic mortality from 31 days of follow-up, which was adjudicated by a panel of physicians who were blinded of treatment allocation. The preliminary results of the CLOSURE 1 trial suggest the PFO occluder device was not superior to the best medical therapy for prevention of recurrent stroke or TIA.

Randomize Evaluation of recurrent Stroke Comparing PFO Closure to Established Current Standard of Care Treatment (RESPECT) is another ongoing PFO occlusion trial [91] (Amplatzer AGA Medical, Plymouth, MN, NCT00465270), and randomizing patients to either best medical therapy or PFO closure on recurrent stroke outcomes. The CLOSE trial (NCT00562289) [92] is comparing anti-thrombotic therapy (anti-platlet $v s$ anticoagulation) $v s$ PFO closure is best in preventing recurrent stroke. Gore-REDUCE trial (NCT00738894) is another randomized clinical trial evaluating PFO closure in secondary stroke prevention. The results of these studies will be very important in patients with $\mathrm{PFO}$ and stroke.

It is also important to note PFO may be a culprit in "parodoxical embolism", which is arterial circulation embolism from venous clots, such as from DVT. The PFOs in these cases can occur from a venous thrombus that crosses through a PFO and instead of causing pulmonary emboli, causes arterial embolic events that resemble cardioembolic stroke.A high degree of clinical suspicion should exist in patients with apparent arterial embolic stroke, but have DVT and PFO. Given the high risk of DVT development after stroke in paretic limbs, the timing of the discovery of DVT and PFO should occur as soon as possible. A paradoxical stroke mechanism should not be attributed when there is obvious mechanism, such as AF. However, in patients with cryptogenic or undefined stroke mechanism, who have a large-sized PFO with shunting on bubble study proving right-to-left sided physiology, and with early detected DVT, paradoxical embolism is sometimes considered. However, there is considerable controversy as to whether paradoxical embolism mechanism exists and how to treat it, especially with a PFO [93, 94]. In young patients with a PFO, a shunt on an echocardiogram, and proven DVT, hypercoaguble workup, and family history should be considered for conditions such as factor $\mathrm{V}$ Leiden, lupus anti-coagulant, prothrombin 20210 mutation, protein $\mathrm{C}$ and protein $\mathrm{S}$ deficiencies, hyperhomocystemia, or anti-cardiolipins hypercoagulable state. A basic prothrombin time (PT) and aPTT can be used to screen for basic hematologic derangements, such as a low aPTT in "lupus anti-coagulant". In such patients, it is important to order the coagulation workup laboratory tests before starting heparin and warfarin, which can affect these tests and confound the diagnosis. In patients with a proven hypercoaguable state, with cerebral embolic event, and a proven early diagnosed DVT and PFO, paradoxical embolism can be considered. Treatment is controversial, but it is typical with anti-coagulation, once safe from a cerebrovascular standpoint, and once the hypercoaguable abnormality is defined.

\section{Future Research into Cardioembolic Stroke}

Imaging

Cardiac CT and MRI are emerging diagnostic tools and have identified sources of cardioembolism missed by conventional echocardiography $[95,96]$, especially for left atrial thrombi. However, cardiac MRI is not widely available, the knowledge among physicians in regard to its approved indications is limited, and it has received poor reimbursement [95]. Current guidelines provide the following indications for cardiac MRI [77, 95]: 1) TTE study is questionable for the presence of left ventricular thrombus; 2) a cardiac mass suspected on TTE requires further

Table 6 Newer anticoagulants for atrial fibrillation for stroke prevention*

\begin{tabular}{lllllll}
\hline Trial & Drug & Design & Size & AF RF & Outcome & Completion month and/or year \\
\hline AVERROES & Apixaban & RCT-DB, DD & 5600 & $\geq 1$ & Stroke, EE, B & June 2010 \\
ARISTOTLE & Apixiban & RCT-DB,DD & 15,000 & $\geq 1$ & Stroke, EE, B & 2010 \\
ENGAGE & Edoxaban & RCT-DB,DD & 16,500 & $\geq 1$ & Stroke, EE, B & 2012 \\
ROCKET & Rivaroxaban & RCT-DB,DD & 14,266 & $\geq 2$ & Stroke, EE, B & 2010 \\
AZD0837 & AZD0837 & RCT, parallel, dose & 250 & $\geq 1$ & Stroke, EE, B & 2010 \\
\hline
\end{tabular}

*Modified from Medi et al. [97].

$\mathrm{AF}=$ atrial fibrillation; $\mathrm{B}=$ bleeding event $\mathrm{DD}=$ double dummy; $\mathrm{EE}=$ embolic event (non-central nervous system); $\mathrm{RCT}-\mathrm{DB}=$ randomized control trial, double blind; $\mathrm{RF}=$ risk factor for ischemic stroke 
evaluation; 3) patients cannot tolerate TEE and/or cannot undergo TEE secondary to medical reasons; 4) the TEE study was inconclusive; and 5) suspected false-negative TEE results, in which a cardiac MRI can adequately image potentially missed sources of embolus, such as left ventricular thrombus, cardiac masses, aortic plaque, or left atrial appendage thrombus.

\section{Newer Anticoagulants}

As previously mentioned, dabigatran is the first of a new line of direct thrombin inhibitors to compete with warfarin for AF, which has been the "anti-coagulation mainstay" for the past 50 years.However, other newer anticoagulants are being investigated in trials [97] and include oral anti-Xa drugs apixiban, edoxaban, rivaroxaban, and the pro-drug AZD0837 (Table 6), which converts into a select and reversible direct thrombin inhibitor (AR-H067637). These newer anticoagulants may provide a wider array for AF patients and ischemic stroke prevention, depending on the results of these trials, which include at least 1 risk factor for stroke, and looking at embolic events both central nervous system (CNS) and non-CNS events, and bleeding.

The results of the Rivaroxaban Once Daily Oral Direct Factor Xa Inhibition Compared with Vitamin K Antagonism for Prevention of Stroke and Embolism Trial in Atrial Fibrillation (ROCKET AF) trial are important to highlight, and these were announced at the American Heart Association's scientific session [98] in November 2010. Rivaroxaban is a direct, competitive factor Xa inhibitor with a half-life of 5 to 13 hours, which has hepatic metabolism (CYP 450) and one third renal clearance. Rivaroxaban has once-daily dosing without the need for coagulation monitoring. The Rivaroxaban Once Daily Oral Direct Factor Xa Inhibition Compared with Vitamin K Antagonism for Prevention of Stroke and Embolism Trial in Atrial Fibrillation (ROCKET AF) trial randomized patients to either rivaroxaban (20 $\mathrm{mg}$ orally, once daily except for patients with creatine clearance of $30-49 \mathrm{ml} / \mathrm{min}$, which received $15 \mathrm{mg}$ daily), or warfarin (INR target, 2.0-3.0) in a double-blind, double-dummy fashion.The primary endpoint was stroke or non-CNS systemic embolism, and major bleeding events in patients with baseline AF (e.g., CHADSscore of $\geq 2$ ). The multicenter, international study enrolled 14,262 patients among 45 countries and 1178 sites $(n=7131$ rivaroxaban and $n=7133$ warfarin). The event rate in the rivaroxaban group was 1.71 compared to 2.16 in the warfarin group (Hazard ratio (HR), 95\% CI, 0.79; 0.66-0.96; with a $p$ value for noninferiority of $<0.001)$. The event rate of hemorrhagic stroke was 0.26 in the rivaroxaban group $v s$ 0.44 in the warfarin group $(p=0.024)$, and ischemic stroke rates of 1.34 and 1.42 , respectively among the groups ( $p=$ 0.581 ). However, the rate of fatal bleeding was lower in the rivaroxaban group (0.24) vs 0.48 in the warfarin group $(0.48)$, which was significantly different $(p=0.003)$. The data suggest that rivaroxaban was not inferior to warfarin for prevention of stroke and non-CNS embolic events, and by intention to treat analysis not superior to warfarin. Rivaroxaban had a similar rate of bleeding, but less fatal and intracranial bleeding than warfarin. Therefore, rivaroxaban (similar to dabigatran) may provide $\mathrm{AF}$ patients a future alternative to warfarin for stroke prevention.

\section{Conclusion}

Cardioembolic stroke is disproportionately more disabling than lacunar stroke due to the occlusion of larger intracranial artery vascular territories and larger brain tissue volume affected. Cardioembolic stroke incidence is expected to increase in the future due to the age-related incidence of AF, which may exceed 12 million patients by 2050. Emerging therapeutic interventions include dabigatran, an oral direct thrombin inhibitor, which has a lower incidence of intracranial bleeding than dose-adjusted warfarin, as well as left atrial appendage obliteration procedures. Future research is also aimed at other oral direct thrombin inhibitors and vitamin $\mathrm{K}$ antagonists that have less or minimal drug interactions. Cardiac MRI may provide an alterative means to diagnose cardioembolic sources of embolism in patients whose detection of such was missed by echocardiogram.

Acknowledgment Full conflict of interest disclosure is available in the electronic supplementary material for this article.

\section{References}

1. Asinger RW, Dyken ML, Fisher M. Cardiogenic brain embolism. The second report of the Cerebral Embolism Task Force. Arch Neurol 1989;46:727-743.

2. Bogousslavsky J, Cachin C, Regli F, et al. Cardiac sources of embolism and cerebral infarction - clinical consequences and vascular concomitants: the Lausanne Stroke Registry. Neurology 1991;41:855-859.

3. Sila CA. Cardioembolic stroke. In: Noseworthy JH, ed. Neurological therapeutics: principles and practice. New York: Martin Dunitz; 2003:450-457.

4. Ferro JM. Cardioembolic stroke: an update. Lancet Neurol 2003;2:177-188.

5. Ramirez-Lassepas M, Cipolle RJ, Bjork RJ, et al. Can embolic stroke be diagnosed on the basis of neurologic clinical criteria? Arch Neurol 1987;44:87-89.

6. Caplan LR. Intracranial branch atheromatous disease: a neglected, understudied, and underused concept. Neurology 1989;39:12461250.

7. Helgason CM. Cardioembolic stroke: topography and pathogenesis. Cerebrovasc Brain Metab Rev 1992;4:28-58. 
8. Minematsu K, Yamaguchi T, Omae T. "Spectacular shrinking deficit" - rapid recovery from a major hemispheric syndrome by migration of an embolus. Neurology 1992;42:157-162.

9. Adams HP Jr., del Zoppo G, Alberts MJ, et al. Guidelines for the early management of adults with ischemic stroke: a guideline from the American Heart Association/American Stroke Association Stroke Council, Clinical Cardiology Council, Cardiovascular Radiology and Intervention Council, and the Atherosclerotic Peripheral Vascular Disease and Quality of Care Outcomes in Research Interdisciplinary Working Groups: The American Academy of Neurology affirms the value of this guideline as an educational tool for neurologists. Circulation 2007;115:e478e534.

10. Alhadramy O, Jeerakathil TJ, Majumdar SR, et al. Prevalence and predictors of paroxysmal atrial fibrillation on Holter monitor in patients with stroke or transient ischemic attack. Stroke 2010;41:2596-2600.

11. Stahrenberg R, Weber-Kruger M, Seegers J, et al. Enhanced detection of paroxysmal atrial fibrillation by early and prolonged continuous holter monitoring in patients with cerebral ischemia presenting in sinus rhythm. Stroke 2010;41:2884-2888.

12. Morris JG, Singh S, Fisher M. Testing for inherited thrombophilias in arterial stroke: can it cause more harm than good? Stroke 2010;41:2985-2990.

13. Harloff A, Handke M, Reinhard M, Geibel A, Hetzel A. Therapeutic strategies after examination by transesophageal echocardiography in 503 patients with ischemic stroke. Stroke 2006;37:859-864.

14. Douglas PS, Khandheria B, Stainback RF, et al. ACCF/ASE/ ACEP/ASNC/SCAI/SCCT/SCMR 2007 appropriateness criteria for transthoracic and transesophageal echocardiography: a report of the American College of Cardiology Foundation Quality Strategic Directions Committee Appropriateness Criteria Working Group, American Society of Echocardiography, American College of Emergency Physicians, American Society of Nuclear Cardiology, Society for Cardiovascular Angiography and Interventions, Society of Cardiovascular Computed Tomography, and the Society for Cardiovascular Magnetic Resonance endorsed by the American College of Chest Physicians and the Society of Critical Care Medicine. J Am Coll Cardiol 2007;50:187-204.

15. Walpot J, Pasteuning WH, Hoevenaar M, et al. Transesophageal echocardiography in patients with cryptogenic stroke: does it alter their management? A 3-year retrospective study in a single non-referral centre. Acta Clin Belg 2006;61:243-248.

16. de Abreu TT, Mateus S, Carreteiro C, Correia J. Therapeutic implications of transesophageal echocardiography after transthoracic echocardiography on acute stroke patients. Vasc Health Risk Manag 2008;4:167-172.

17. Tong DC, Bolger A, Albers GW. Incidence of transcranial Doppler-detected cerebral microemboli in patients referred for echocardiography. Stroke 1994;25:2138-2141.

18. Caplan LR, Hier DB, D'Cruz I. Cerebral embolism in the Michael Reese Stroke Registry. Stroke 1983;14:530-536.

19. Arboix A, Oliveres M, Massons J, Pujades R, Garcia-Eroles L. Early differentiation of cardioembolic from atherothrombotic cerebral infarction: a multivariate analysis. Eur J Neurol 1999;6:677-683.

20. Caplan L. Posterior circulation ischemia: then, now, and tomorrow. The Thomas Willis Lecture-2000. Stroke 2000;31:2011-2023.

21. Bogousslavsky J, Regli F, Maeder P, Meuli R, Nader J. The etiology of posterior circulation infarcts: a prospective study using magnetic resonance imaging and magnetic resonance angiography. Neurology 1993;43:1528-1533.

22. Caplan LR, Wityk RJ, Glass TA, et al. New England Medical Center Posterior Circulation registry. Ann Neurol 2004;56:389-398.
23. Glass TA, Hennessey PM, Pazdera L, et al. Outcome at 30 days in the New England Medical Center Posterior Circulation Registry. Arch Neurol 2002;59:369-376.

24. Schonewille WJ, Wijman CA, Michel P, Algra A, Kappelle LJ. The basilar artery international cooperation study (BASICS). Int J Stroke 2007;2:220-223.

25. Pessin MS, Lathi ES, Cohen MB, et al. Clinical features and mechanism of occipital infarction. Ann Neurol 1987;21:290-299.

26. Yamamoto Y, Georgiadis AL, Chang HM, Caplan LR. Posterior cerebral artery territory infarcts in the New England Medical Center Posterior Circulation Registry. Arch Neurol 1999;56:824-832.

27. Adams HP Jr., Bendixen BH, Kappelle LJ, et al. Classification of subtype of acute ischemic stroke. Definitions for use in a multicenter clinical trial. TOAST. Trial of Org 10172 in Acute Stroke Treatment. Stroke 1993;24:35-41.

28. Elijovich L, Josephson SA, Fung GL, Smith WS. Intermittent atrial fibrillation may account for a large proportion of otherwise cryptogenic stroke: a study of 30-day cardiac event monitors. J Stroke Cerebrovasc Dis 2009;18:185-189.

29. Tayal AH, Tian M, Kelly KM, et al. Atrial fibrillation detected by mobile cardiac outpatient telemetry in cryptogenic TIA or stroke. Neurology 2008;71:1696-1701.

30. Gaillard N, Deltour S, Vilotijevic B, et al. Detection of paroxysmal atrial fibrillation with transtelephonic EKG in TIA or stroke patients. Neurology 2010;74:1666-1670.

31. Montaner J, Perea-Gainza M, Delgado P, et al. Etiologic diagnosis of ischemic stroke subtypes with plasma biomarkers. Stroke 2008;39:2280-2287.

32. Shibazaki K, Kimura K, Iguchi Y, Okada Y, Inoue T. Plasma brain natriuretic peptide can be a biological marker to distinguish cardioembolic stroke from other stroke types in acute ischemic stroke. Intern Med 2009;48:259-264.

33. Miyasaka Y, Barnes ME, Gersh BJ, et al. Secular trends in incidence of atrial fibrillation in Olmsted County, Minnesota, 1980 to 2000, and implications on the projections for future prevalence. Circulation 2006;114:119-125.

34. Fuster V, Ryden LE, Cannom DS, et al. ACC/AHA/ESC 2006 guidelines for the management of patients with atrial fibrillation executive summary: a report of the American College of Cardiology/American Heart Association Task Force on Practice Guidelines and the European Society of Cardiology Committee for Practice Guidelines (Writing Committee to Revise the 2001 Guidelines for the Management of Patients With Atrial Fibrillation). [Erratum appears in J Am Coll Cardiol 2007;50:562]. J Am Coll Cardiol 2006;48:854-906.

35. Feinberg WM, Blackshear JL, Laupacis A, Kronmal R, Hart RG. Prevalence, age distribution, and gender of patients with atrial fibrillation. Analysis and implications. Arch Intern Med 1995; 155:469-473.

36. Connolly S, Pogue J, Hart R, et al. Clopidogrel plus aspirin versus oral anticoagulation for atrial fibrillation in the Atrial fibrillation Clopidogrel Trial with Irbesartan for prevention of Vascular Events (ACTIVE W): a randomised controlled trial. Lancet 2006;367:1903-1912.

37. Hohnloser SH, Pajitnev D, Pogue J, et al. Incidence of stroke in paroxysmal versus sustained atrial fibrillation in patients taking oral anticoagulation or combined antiplatelet therapy: an ACTIVE W Substudy. J Am Coll Cardiol 2007;50:2156-2161.

38. Go AS, Hylek EM, Phillips KA, et al. Prevalence of diagnosed atrial fibrillation in adults: national implications for rhythm management and stroke prevention: the AnTicoagulation and Risk Factors in Atrial Fibrillation (ATRIA) Study. JAMA 2001;285:2370-2375.

39. Wolf PA, Abbott RD, Kannel WB. Atrial fibrillation as an independent risk factor for stroke: the Framingham Study. Stroke 1991;22:983-988. 
40. The Boston Area Anticoagulation Trial for Atrial Fibrillation Investigators. The effect of low-dose warfarin on the risk of stroke in patients with nonrheumatic atrial fibrillation. The Boston Area Anticoagulation Trial for Atrial Fibrillation Investigators. N Engl J Med 1990;323:1505-1511.

41. Stroke Prevention in Atrial Fibrillation Investigators. Stroke Prevention in Atrial Fibrillation Study. Final results. Circulation 1991;84:527-539.

42. The SPAF III Writing Committee for the Stroke Prevention in Atrial Fibrillation Investigators. Patients with nonvalvular atrial fibrillation at low risk of stroke during treatment with aspirin: Stroke Prevention in Atrial Fibrillation III Study. JAMA 1998;279:1273-1277.

43. Petersen P, Boysen G, Godtfredsen J, Andersen ED, Andersen B. Placebo-controlled, randomised trial of warfarin and aspirin for prevention of thromboembolic complications in chronic atrial fibrillation. The Copenhagen AFASAK study. Lancet 1989;1:175-179.

44. Connolly SJ, Laupacis A, Gent M, et al. Canadian Atrial Fibrillation Anticoagulation (CAFA) Study. J Am Coll Cardiol 1991;18:349-355.

45. Pearce LA, Hart RG, Halperin JL. Assessment of three schemes for stratifying stroke risk in patients with nonvalvular atrial fibrillation. Am J Med 2000;109:45-51.

46. Gage BF, Waterman AD, Shannon W, et al. Validation of clinical classification schemes for predicting stroke: results from the National Registry of Atrial Fibrillation. JAMA 2001;285:28642870.

47. Atrial Fibrillation Investigators: Atrial Fibrillation, Aspirin, Anticoagulation Study; Boston Area Anticoagulation Trial for Atrial Fibrillation Study; Canadian Atrial Fibrillation Anticoagulation Study; Stroke Prevention in Atrial Fibrillation Study; Veterans Affairs Stroke Prevention in Nonrheumatic Atrial Fibrillation Study. Risk factors for stroke and efficacy of antithrombotic therapy in atrial fibrillation. Analysis of pooled data from five randomized controlled trials. [Erratum appears in Arch Intern Med 1994;154:2254]. Arch Intern Med 1994;154:1449-1457.

48. Ezekowitz MD, Levine JA. Preventing stroke in patients with atrial fibrillation. JAMA 1999;281:1830-1835.

49. Laupacis A, Albers G, Dalen J, et al. Antithrombotic therapy in atrial fibrillation. Chest 1998;114:579S-589S.

50. Hart RG, Pearce LA, Aguilar MI. Meta-analysis: antithrombotic therapy to prevent stroke in patients who have nonvalvular atrial fibrillation. Ann Intern Med 2007;146:857-867.

51. Secondary prevention in non-rheumatic atrial fibrillation after transient ischaemic attack or minor stroke. EAFT (European Atrial Fibrillation Trial) Study Group. Lancet 1993;342:12551262.

52. Hart RG, Benavente O, McBride R, Pearce LA. Antithrombotic therapy to prevent stroke in patients with atrial fibrillation: a meta-analysis. Ann Intern Med 1999;131:492-501.

53. Aguilar M, Hart R. Antiplatelet therapy for preventing stroke in patients with non-valvular atrial fibrillation and no previous history of stroke or transient ischemic attacks. Cochrane Database Syst Rev 2005:CD001925.

54. Gullov AL, Koefoed BG, Petersen P, et al. Fixed minidose warfarin and aspirin alone and in combination vs adjusted-dose warfarin for stroke prevention in atrial fibrillation: Second Copenhagen Atrial Fibrillation, Aspirin, and Anticoagulation Study. Arch Intern Med 1998;158:1513-1521.

55. Hellemons BS, Langenberg M, Lodder J, et al. Primary prevention of arterial thromboembolism in non-rheumatic atrial fibrillation in primary care: randomised controlled trial comparing two intensities of coumarin with aspirin. BMJ 1999;319:958-964.
56. Vemmos KN, Tsivgoulis G, Spengos K, et al. Primary prevention of arterial thromboembolism in the oldest old with atrial fibrillation a randomized pilot trial comparing adjusted-dose and fixed lowdose coumadin with aspirin. Eur J Intern Med 2006;17:48-52.

57. Hu DY, Zhang HP, Sun YH, Jiang LQ. [The randomized study of efficiency and safety of antithrombotic therapy in nonvalvular atrial fibrillation: warfarin compared with aspirin]. Zhonghua Xin Xue Guan Bing Za Zhi 2006;34:295-298.

58. Rash A, Downes T, Portner R, et al. A randomised controlled trial of warfarin versus aspirin for stroke prevention in octogenarians with atrial fibrillation (WASPO). Age Ageing 2007;36:151-156.

59. Perez-Gomez F, Alegria E, Berjon J, et al. Comparative effects of antiplatelet, anticoagulant, or combined therapy in patients with valvular and nonvalvular atrial fibrillation: a randomized multicenter study. J Am Coll Cardiol 2004;44:1557-1566.

60. Stroke Prevention in Atrial Fibrillation Investigators. Adjusted-dose warfarin versus low-intensity, fixed-dose warfarin plus aspirin for high-risk patients with atrial fibrillation: Stroke Prevention in Atrial Fibrillation III randomised clinical trial. Lancet 1996;348:633-638.

61. Albers GW, Amarenco P, Easton JD, Sacco RL, Teal P. Antithrombotic and thrombolytic therapy for ischemic stroke: the Seventh ACCP Conference on Antithrombotic and Thrombolytic Therapy. Chest 2004;126:483S-512S.

62. Connolly SJ, Pogue J, Hart RG, et al. Effect of clopidogrel added to aspirin in patients with atrial fibrillation. $\mathrm{N}$ Engl $\mathrm{J}$ Med 2009;360:2066-2078.

63. Mant J, Hobbs FD, Fletcher K, et al. Warfarin versus aspirin for stroke prevention in an elderly community population with atrial fibrillation (the Birmingham Atrial Fibrillation Treatment of the Aged Study, BAFTA): a randomised controlled trial. Lancet 2007;370:493-503.

64. Singer DE, Chang Y, Fang MC, et al. The net clinical benefit of warfarin anticoagulation in atrial fibrillation. Ann Intern Med 2009;151:297-305

65. Akins PT, Feldman HA, Zoble RG, et al. Secondary stroke prevention with ximelagatran versus warfarin in patients with atrial fibrillation: pooled analysis of SPORTIF III and V clinical trials. Stroke 2007;38:874-880.

66. Albers GW, Diener HC, Frison L, et al. Ximelagatran vs warfarin for stroke prevention in patients with nonvalvular atrial fibrillation: a randomized trial. JAMA 2005;293:690-698.

67. Olsson SB. Stroke prevention with the oral direct thrombin inhibitor ximelagatran compared with warfarin in patients with non-valvular atrial fibrillation (SPORTIF III): randomised controlled trial. Lancet 2003;362:1691-1698.

68. Connolly SJ, Ezekowitz MD, Yusuf S, et al. Dabigatran versus warfarin in patients with atrial fibrillation. $\mathrm{N}$ Engl J Med 2009;361:1139-1151.

69. Dabigatran (Pradaxa) [Package Insert]: Boehringer Ingelheim Pharmaceuticals, Inc.; 2010.

70. FDA approves Pradaxa to prevent stroke in people with atrial fibrillation. In: FDA News Release [online], October 10, 2010. Available at: http://www.fda.gov/NewsEvents/Newsroom/Press Announcements/ucm230241.htm. Accessed November 10, 2010.

71. Freeman WD, Aguilar MI, Weitz J. Risk of intracerebral hemorrhage in patients treated with warfarin. In: UpToDate database. Waltham, MA: UpToDate, Inc.; January 2010; Available at: http://www.uptodate.com/contents/risk-of-intracerebralhemorrhage-in-patients-treated-with-warfarin? source=search result\&selectedTitle=1\%7E150. Accessed November 14, 2010.

72. Connolly SJ, Eikelboom J, Joyner C, et al. Apixaban in patients with atrial fibrillation. N Engl J Med 2011;364:806-817.

73. Ellis DJ, Usman MH, Milner PG, Canafax DM, Ezekowitz MD. The first evaluation of a novel vitamin $\mathrm{K}$ antagonist, tecarfarin (ATI-5923), in patients with atrial fibrillation. Circulation 2009;120:1029-1035. 
74. Crandall MA, Bradley DJ, Packer DL, Asirvatham SJ. Contemporary management of atrial fibrillation: update on anticoagulation and invasive management strategies. Mayo Clin Proc 2009;84:643-662.

75. Cruz-Gonzalez I, Yan BP, Lam YY. Left atrial appendage exclusion: state-of-the-art. Catheter Cardiovasc Interv 2010;75:806-813.

76. "Left atrial occlusion" search. ClinicalTrials.gov [online]. Available at:http://clinicaltrials.gov/ct2/results?term=left+atrial+occlusion. Accessed November 14, 2010.

77. Freeman WD, Aguilar MI, Weitz J. Stroke prevention in atrial fibrillation and other major cardiac sources of embolism. Neurol Clin 2008;26:1129-1160.

78. Working Party on Anticoagulant Therapy in Coronary Thrombosis. Assessment of short-anticoagulant administration after cardiac infarction. Report of the Working Party on Anticoagulant Therapy in Coronary Thrombosis to the Medical Research Council. Br Med J 1969;1:335-342.

79. Anticoagulants in acute myocardial infarction. Results of a cooperative clinical trial. JAMA 1973;225:724-729.

80. Effect of long-term oral anticoagulant treatment on mortality and cardiovascular morbidity after myocardial infarction. Anticoagulants in the Secondary Prevention of Events in Coronary Thrombosis (ASPECT) Research Group. Lancet 1994;343:499-503.

81. Cairns JA, Theroux P, Lewis HD Jr., et al. Antithrombotic agents in coronary artery disease. Chest 1998;114:611S-633S.

82. Drapkin A, Merskey C. Anticoagulant therapy after acute myocardial infarction. Relation of therapeutic benefit to patient's age, sex, and severity of infarction. JAMA 1972;222:541-548.

83. Young JB. Chronic heart failure management. In: Topol EJ, ed. Comprehensive Cardiovascular Medicine. Philadelphia: Lippincott-Raven; 1998.

84. Di Tullio MR, Homma S. Mechanisms of cardioembolic stroke. Curr Cardiol Rep 2002;4:141-148.

85. Schwedt TJ, Demaerschalk BM, Dodick DW. Patent foramen ovale and migraine: a quantitative systematic review. Cephalalgia 2008;28:531-540.

86. Maisel WH, Laskey WK. Patent foramen ovale closure devices: moving beyond equipoise. JAMA 2005;294:366-369.

87. Homma S, Sacco RL, Di Tullio MR, Sciacca RR, Mohr JP. Effect of medical treatment in stroke patients with patent foramen ovale: patent foramen ovale in Cryptogenic Stroke Study. Circulation 2002;105:2625-2631.

88. Messe SR, Silverman IE, Kizer JR, et al. Practice parameter: recurrent stroke with patent foramen ovale and atrial septal aneurysm: report of the Quality Standards Subcommittee of the American Academy of Neurology. Neurology 2004;62:1042-1050.

89. CLOSURE 1 Trial results. Medscape, LLC [online]; 2010. Available at: http://www.theheart.org/article/1088789.do. Accessed November 10, 2010.

90. Furlan AJ, Reisman M, Massaro J, et al. Study design of the CLOSURE I Trial: a prospective, multicenter, randomized, controlled trial to evaluate the safety and efficacy of the STARFlex septal closure system versus best medical therapy in patients with stroke or transient ischemic attack due to presumed paradoxical embolism through a patent foramen ovale. Stroke 2010;41:2872-2883.

91. RESPECT PFO Clinical Trial. ClinicalTrials.gov [online]; 2010. Available at: http://clinicaltrials.gov/ct2/show/NCT00465270. Accessed November 14, 2010.

92. Patent Foramen Ovale Closure or Anticoagulants Versus Antiplatelet Therapy to Prevent Stroke Recurrence (CLOSE) Trial. ClinicalTrials.gov [online]; 2010. Available from: http://clinical trials.gov/ct2/show/NCT00562289. Accessed November 14, 2010.

93. Itoh T, Matsumoto M, Handa N, et al. Paradoxical embolism as a cause of ischemic stroke of uncertain etiology. A transcranial Doppler sonographic study. Stroke 1994;25:771-775.
94. Myers PO, Bounameaux H, Panos A, Lerch R, Kalangos A. Impending paradoxical embolism: systematic review of prognostic factors and treatment. Chest 2010;137:164-170.

95. Hendel RC, Patel MR, Kramer CM, et al. ACCF/ACR/SCCT/ SCMR/ASNC/NASCI/SCAI/SIR 2006 appropriateness criteria for cardiac computed tomography and cardiac magnetic resonance imaging: a report of the American College of Cardiology Foundation Quality Strategic Directions Committee Appropriateness Criteria Working Group, American College of Radiology, Society of Cardiovascular Computed Tomography, Society for Cardiovascular Magnetic Resonance, American Society of Nuclear Cardiology, North American Society for Cardiac Imaging, Society for Cardiovascular Angiography and Interventions, and Society of Interventional Radiology. J Am Coll Cardiol 2006;48:1475-1497.

96. Rustemli A, Bhatti TK, Wolff SD. Evaluating cardiac sources of embolic stroke with MRI. Echocardiography 2007;24:301-308.

97. Medi C, Hankey GJ, Freedman SB. Stroke risk and antithrombotic strategies in atrial fibrillation. Stroke 2010;41:2705-2713.

98. Mahaffey KW, Fox K, Investigators obotRA, eds. Rivaroxaban comparable to warfarin in preventing stroke and other complications of irregular heartbeat. American Heart Association. Available at:http://www.newsroom.heart.org/index.php? $\mathrm{s}=43 \&$ item $=1191$. November 15,2010 .

99. Orencia AJ, Hammill SC, Whisnant JP. Sinus node dysfunction and ischemic stroke. Heart Dis Stroke 1994;3:91-94.

100. Mosterd A, Hoes AW, de Bruyne MC, et al. Prevalence of heart failure and left ventricular dysfunction in the general population; The Rotterdam Study. Eur Heart J 1999;20:447-455.

101. Witt BJ, Brown RD Jr., Jacobsen SJ, et al. Ischemic stroke after heart failure: a community-based study. Am Heart J 2006;152:102-109.

102. Loh E, Sutton MS, Wun CC, et al. Ventricular dysfunction and the risk of stroke after myocardial infarction. N Engl J Med 1997;336:251-257.

103. Anderson GM, Hull E. The effect of dicumarol upon the mortality and incidence of thromboembolic complications in congestive heart failure. Am Heart J 1950;39:697-702.

104. Griffith GC, Stragnell R, Levinson DC, Moore FJ, Ware AG. A study of the beneficial effects of anticoagulant therapy in congestive heart failure. Ann Intern Med 1952;37:867-887.

105. Harvey WP, Finch CA. Dicumarol prophylaxis of thromboembolic disease in congestive heart failure. $\mathrm{N}$ Engl $\mathrm{J}$ Med 1950;242:208-211.

106. Georgiadis D, Sievert M, Cencetti S, et al. Cerebrovascular reactivity is impaired in patients with cardiac failure. Eur Heart $\mathbf{J}$ 2000;21:407-413.

107. Alves TC, Rays J, Fraguas R Jr., et al. Localized cerebral blood flow reductions in patients with heart failure: a study using 99mTc-HMPAO SPECT. J Neuroimaging 2005;15:150-156.

108. Hays AG, Sacco RL, Rundek T, et al. Left ventricular systolic dysfunction and the risk of ischemic stroke in a multiethnic population. Stroke 2006;37:1715-1719.

109. Dries DL, Rosenberg YD, Waclawiw MA, Domanski MJ. Ejection fraction and risk of thromboembolic events in patients with systolic dysfunction and sinus rhythm: evidence for gender differences in the studies of left ventricular dysfunction trials. [Erratum appears in J Am Coll Cardiol 1998;32:555]. J Am Coll Cardiol 1997;29:1074-1080.

110. Koniaris LS, Goldhaber SZ. Anticoagulation in dilated cardiomyopathy. J Am Coll Cardiol 1998;31:745-748.

111. Dunkman WB, Johnson GR, Carson PE, et al. Incidence of thromboembolic events in congestive heart failure. The V-HeFT VA Cooperative Studies Group. Circulation 1993;87:VI94-101.

112. Kyrle PA, Korninger C, Gossinger H, et al. Prevention of arterial and pulmonary embolism by oral anticoagulants in patients with dilated cardiomyopathy. Thromb Haemost 1985;54:521-523. 
113. Massie BM, Krol WF, Ammon SE, et al. The Warfarin and Antiplatelet Therapy in Heart Failure trial (WATCH): rationale, design, and baseline patient characteristics. J Card Fail 2004;10:101-112.

114. Massie BM, Collins JF, Ammon SE, et al. Randomized trial of warfarin, aspirin, and clopidogrel in patients with chronic heart failure: the Warfarin and Antiplatelet Therapy in Chronic Heart Failure (WATCH) trial. Circulation 2009;119:1616-1624.

115. Pullicino P, Thompson JL, Barton B, et al. Warfarin versus aspirin in patients with reduced cardiac ejection fraction (WARCEF): rationale, objectives, and design. J Card Fail 2006;12:39-46.

116. Bonow RO, Carabello BA, Chatterjee K, et al. ACC/AHA 2006 guidelines for the management of patients with valvular heart disease: a report of the American College of Cardiology/ American Heart Association Task Force on Practice Guidelines (writing Committee to Revise the 1998 guidelines for the management of patients with valvular heart disease) developed in collaboration with the Society of Cardiovascular Anesthesiologists endorsed by the Society for Cardiovascular Angiography and Interventions and the Society of Thoracic Surgeons. J Am Coll Cardiol 2006;48:e1-e148.

117. Mills P, Leech G, Davies M, Leathan A. The natural history of a non-stenotic bicuspid aortic valve. Br Heart J 1978;40:951-957.

118. Salem DN, Levine HJ, Pauker SG, Eckman MH, Daudelin DH. Antithrombotic therapy in valvular heart disease. Chest 1998;114:590S-601S

119. Salgado AV, Furlan AJ, Salcedo E. Risk of stroke in patients with congenital bicuspid valve. J Stroke Cerebrovasc Dis 1991;1:6163.

120. Stein PD, Dalen JE, Goldman S, Theroux P. Antithrombotic therapy in patients with saphenous vein and internal mammary artery bypass grafts. Chest 1998;114:658S-665S.

121. Davidson CJ, Skelton TN, Kisslo KB, et al. The risk for systemic embolization associated with percutaneous balloon valvuloplasty in adults. A prospective comprehensive evaluation. Ann Intern Med 1988;108:557-560.

122. Petty GW, Orencia AJ, Khandheria BK, Whisnant JP. A population-based study of stroke in the setting of mitral valve prolapse: risk factors and infarct subtype classification. Mayo Clin Proc 1994;69:632-634.
123. Wolf PA, Sila CA. Cerebral ischemia with mitral valve prolapse. Am Heart J 1987;113:1308-1315.

124. Stein PD, Alpert JS, Dalen JE, Horstkotte D, Turpie AG. Antithrombotic therapy in patients with mechanical and biological prosthetic heart valves. Chest 1998;114:602S-610S.

125. Landing BH, Farber S. Tumors of the Cardiovascular System. Atlas of Tumor Pathology, 1st ed. Washington, D.C.: Armed Forces Institute of Pathology; 1956.

126. Reynen K. Frequency of primary tumors of the heart. Am J Cardiol 1996;77:107.

127. Aziz F, Baciewicz FA, Jr. Lambl's excrescences: review and recommendations. Tex Heart Inst J 2007;34:366-368.

128. Dismukes WE. Management of infective endocarditis. Cardiovasc Clin 1981;11:189-208.

129. Fleming HA. General principles of the treatment of infective endocarditis. J Antimicrob Chemother 1987;20(suppl A):143145.

130. Hart RG, Foster JW, Luther MF, Kanter MC. Stroke in infective endocarditis. Stroke 1990;21:695-700.

131. Prabhakaran S. Neurologic complications of endocarditis CONTINUUM: Lifelong Learning in Neurology 2008;14:53-73.

132. Robbins MJ, Eisenberg ES, Frishman WH. Infective endocarditis: a pathophysiologic approach to therapy. Cardiol Clin 1987;5:545-562.

133. Salgado AV, Furlan AJ, Keys TF, Nichols TR, Beck GJ. Neurologic complications of endocarditis: a 12-year experience. Neurology 1989;39:173-178.

134. Reynen K. Cardiac myxomas. N Engl J Med 1995;333:1610-1617.

135. Kizer JR, Devereux RB. Clinical practice. Patent foramen ovale in young adults with unexplained stroke. [Erratum appears in $\mathrm{N}$ Engl J Med 2006;354:2401]. N Engl J Med 2005;353:23612372.

136. Mas JL, Arquizan C, Lamy C, et al. Recurrent cerebrovascular events associated with patent foramen ovale, atrial septal aneurysm, or both. N Engl J Med 2001;345:1740-1746.

137. Handke M, Harloff A, Olschewski M, Hetzel A, Geibel A. Patent foramen ovale and cryptogenic stroke in older patients. N Engl J Med 2007;357:2262-2268.

138. Freeman WD, Aguilar M. Anticoagulation therapy for cardioembolic stroke prevention in the elderly: defining benefits and risks. Aging Health 2010;6:439-450. 